\title{
Optimal Sliding Mode Control of Permanent Magnet Direct Drive Linear Generator for Grid-Connected Wave Energy Conversion
}

\author{
Adel Elgammal and Curtis Boodoo
}

\begin{abstract}
- the key goal of this article is on the design and optimum sliding mode control for Grid-Connected direct drive extraction method of ocean wave energy by Multi-Objective Particle Swarm Optimization (MOPSO). A Linear Permanent Magnet Generator simulates the ocean wave energy extraction system, driven by an Archimedes Wave Swing. Uncontrolled three-phase rectifiers, a three-level buck-boost converter and 3 level neutral point clamped inverter are planned grid integration of Wave Energy Conversion device. The technique monitors the three-level buck-boost converter service cycle linked to the PMLG output terminals and decides the optimum switching sequence of 3 level neutral point clamped inverter to enable the grid relation. Simulations using Matlab/Simulink were carried out to test working of the wave energy converter after the suggested optimal control method was applied under various operating settings. Various simulation test results indicate that the proposed optimum control system is tested in both normal and irregular ocean waves. And it has been shown that the control method of the MOPSO sliding mode is ideal for maximizing energy transfer efficiency. Better voltage management at the DC-link and for achieving greater controllability spectrum was accomplished by the proposed Duty-ratio optimal control system.
\end{abstract}

Index Terms- Sliding Mode Control, Multi-Objective Particle Swarm Optimization (MOPSO), Archimedes Wave Swing (AWS), Linear Permanent Magnet Generator, Wave Energy Conversion.

\section{INTRODUCTION}

One of the large energies that can be converted into electric power is ocean wave energy. They allow machines to produce more power at lower costs from a smaller amount and reduce visual effects [1], [2]. In recent years, energy production from sea waves has attracted a lot of interest. It has become one of the research areas with the fastest growth [3]. This is also one of the most challenging energy resources to interface with the grid because of the complexity in the energy extraction mechanism and the highly random nature of input energy [4]. The essential requirement to capture this energy is the right technology at the right place. Several technologies have already been developed and validated around the world for wave energy converters [5]. The technologies vary in operating methodology as well as in physical dimensions. Classifications of such technologies are made based on various factors. Distance of the WECs from the shore can be one of the criteria, based on which they are classified into onshore, near shore and offshore technologies. The type of power absorption method can be other criteria, where

Published on February 8, 2021

Adel Elgammal, The University of Trinidad and Tobago UTT, Utilities Engineering, Point Lisas Campus, Trinidad and Tobago. different systems are classified into point absorbers, attenuators, overtopping devices etc. [6], [7].

In order to effectively transform wave energy into electrical energy, there are various types of converters of ocean wave energy have been developed and tested [8], [9]. The wave energy unit can have a translation or rotational form and both of these systems has distinct structures [10]. In transforming the intermittent wave motion for energy conversion to periodic motion, the power take-off tools play a critical part. Without using intermediate size devices, linear generators have been expressly introduced to transmit direct drive wave energy and have distinct benefits over all other wave energy products [11]. For better efficiency, various types of permanent magnet linear generators are being produced and studied. It has been proposed to use permanent magnet linear generators for flat and tubular flux switching [12], [13]. Several tests have shown that the steel cores and FSPMLGs built PMs have struggled from the issue of an increased leakage flux contributing to a decline in the generation of electrical power. To decrease cogging forces and also increase performance, tubular PMLGs have been suggested [14], [15]. Because of the existence of the coils within the periphery, treatment of tubular PMLG is complicated. For high power generation, the linear switched reluctance generator was suggested in its most early projects [16]. The loss of overall performance and reliability is caused by unnecessary leakage flux and complicated LSRG control circuits.

The most up-to-date technology for the production of ocean energy comprise of the forms of WECs, control systems, electrical generators, controller construction spots used, ocean wave dynamics, methods of power conversion and functional validation [17]. Any of these are studied using latching control techniques, linear quadrature Gaussian design topology, adjustable tuning and reactive power and adaptive inertia among various control methodologies [18]. To achieve utmost electrical energy via PMLG regulating reaction force, a control technique was developed [19]. To pass full energy from the generator to the utility grid, sensor less control structure is expected [20]. Feedback on linear slider displacement and measurement of EMF by means of sensing coils is needed. There are daunting problems with extraction of absolute electric power using direct drive WEDs with flexible load requirements. [21], [22]. Through managing both the hardware and the software parts, these problems can be mitigated. The challenges of the control mechanisms, longevity, and the expense of the WEDs impact

(e-mail: adel_elgammal2000@yahoo.com)

Curtis Boodoo, The University of Trinidad and Tobago UTT, Utilities Engineering, Point Lisas Campus, Trinidad and Tobago. 
the use of full OWEE [23]. Utilizing direct drive PMLG along sub optimal control technology, Optimal Owing can be derived from real sea conditions [24]. The utility of optimum Owing extraction is provided by control technology that provides reactive control methods [25]. A control principle is designed with the goal of OWE harvesting, taking into account the vector control method of the PMLG to regulate the electromotive force [26]. In order to monitor the role of wave energy conversions mounted in an array configuration, a centralized model predictive control methodology is developed. [27]. Compared to decentralized MPC and restraining force controller, the effectiveness of the engineered control system was found to be more stable given normal along with irregular ocean wave settings. For specific point absorber based wave energy distribution systems that incorporate floating buoy configuration, another MPC framework is suggested [28]. Due to some realistic features, such as the wavering force and velocity of the power take-off device, it is used for full harvesting. It is advised to use a predictive current control concept in which the predicted load inductance inaccuracies are more accurate [29]. At very low electromotive force conditions and zero current, this approach also decreases the unstable effect. [30], [31]. By recognizing the wave energy conversion and heaving motion of float's very fast action, damping force management procedure is planned and actually tested [32]. An innovative resonance control algorithm is developed for AWS centred wave energy conversion to combine both the PTO damping force and the stiffness force [33]. A correctly built voltage regulator is often focused in detail to preserve a steady decoupled voltage around the capacitor. The functionality and working of the WECs have been compromised by the regulatory procedure that controls the dynamic activity of the PTO [43]. Various predictive management strategies are intended to achieve advanced WED adeptness, including copper deficit for the period of the WECs optimization procedure [35]. Conversely, by controlling the energy flow in one direction, the latching power system, which is the replacement principle of reactive regulation, reduces electrical generator losses [36]. To control float escape, the realistic implementation of latching control technology includes forecasting knowledge on ocean wave properties [37]. The skills of both reactive control and the latching techniques can be strengthened by taking into account the shortcomings of the excursion of wave energy conversion during the control system scheme under irregular wave characteristics [38]. Unbalanced voltage problems can be created due to the direct introduction of distributed renewable sources into the utility service [39].

An effective and practical optimal control technique is proposed in this article for controlling a Grid-Connected direct drive ocean wave energy extraction method. The projected method is built on the MOPSO sliding mode control to maximize DC power transfer on the electrical side of the WEC. The proposed WEC system is composed of a three phase linear generator of permanent magnet and related threephase boost rectifier. By controlling the operating period of the switching signal feed to the boost rectifier, the electrical and mechanical dynamics of the WEC can be regulated. In terms of computation, the proposed optimization strategy for closed loop regulation is straightforward and inexpensive and takes account of the variations in both the maritime environment and the electrical loading conditions of the WEC.

\section{DESCRIPTION OF PROPOSED SYSTEM}

The Archimedes wave swing, which contributes to greater energy transfer efficiency, to implement the direct drive power takes off technique is the first wave energy conversion method. Using the LPMG, wave energy can be converted into electric energy. Two key components are used in the LPMG, namely the translator and the stator. As seen in Fig. 1, the interpreter mounted on a hollow cylinder is often called a float. To hold it stable with respect to the sea wave, the stator is attached to another mechanical entity. The floater seeks to float on the ocean wave bottom with the interpreter, which varies due to wave action according to the stator. At a single stage, the floater uses the increase and decrease of the sea wave for energy transfer. The wave energy thus derived is transformed into electrical energy when the translator travels linearly because of the floater's reciprocating motion. The kinetic energy in the heave movement of the point absorber/buoy is used for electricity production in the principle of wave energy converter technology of directdriven point absorber style. The linear underwater generator is mounted on the seabed on a concrete base. Permanent magnets are placed on the rotating portion of the motor, called the translator, which uses a flexible steel cord to attach to the point absorber. The magnetic flux relation in the stator coil varies accordingly due to the up-down movement of translator along with floating buoy, as well as its sign when the translator shifts each pole pitch. An EMF is thus generated in the winding of stator. The output voltage of generator varies according to translator-stator interaction in its magnitude and phase, which in turn results from wave motion.

Because LPMG's translator reciprocates, the position and pace of the translator's motion differ. Subsequently, the induced stator and voltage current along with output power differ in magnitude and frequency. The Gird code for integrating wave generation into the power network cannot satisfy these features of the linear permanent magnet generator. The power conditioner should, however, be programmed to integrate the AWS centred WEC into the power grids.

In a converter known as the generator side power converter, the generated voltage is applied. The static stator and linear sliding translator are the key components of the PMLG, which typically comprises of coil of wires. In the presence of a magnetic field, the voltage in the stator windings is generated because of relative linear motion among the slider and the stator windings. With respect to the stator, the interpreter generates a variable relative velocity due to oscillating oceanic waves. As a consequence, there is no steady frequency and amplitude for the induced AC voltage. As a variable AC signal from the WEC output is input to power converter and required output is the standard utility signal, the need for an AC/AC conversion unit is apparent. A multi-stage power converter system, consisting of an $\mathrm{AC} / \mathrm{DC}$ (rectifier) converter as the first stage, DC/AC inverter and a middle DC/DC converter as final stage to allow 
the grid connection, is more commonly used for such applications. After multi-stage (AC-DC-AC) power conversion, the synchronization of the grid is ensured. Grid integration of any renewable energy source needs a power converter system which can produce a stable sinusoidal $60 \mathrm{~Hz}$ standard utility output voltage and current, irrespective of its input signal type. It must ensure that all the grid codes are satisfied when connecting the renewables to the grid. The WEC is a point absorber type direct driven linear machine without any hydraulics and gear system. That makes it a very simple, compact, efficient and cheap solution for the wave energy absorption. Due to the same reason, the generator electrical output reflects the exact random nature of the wave energy input. Thus, the power conversion system must handle the high fluctuations in voltage, frequency and phase of the LPMG output and provide a stable sinusoidal standard utility output. To form the DC-link, three-phase diode bridge rectifier units are interconnected. Even though they are uncontrolled rectifiers, the attention is given to the interconnection strategies to form stable DC-link. The focus is given to DC-link power conditioning to form DC-link where three-level buck-boost converters with smart control techniques are used. The final grid coupling stage is designed using an inverter-clamped three-level neutral point where several improvements are also incorporated compared to conventional grid-tied system.

In Fig. 2, a standard grid communication interface is provided for use with generator applications. This stage consists of a bipolar transistor (IGBT) inverter with a sixpulse insulated gate. In order to synchronize output voltage of inverter with grid quantities, such as voltage amplitude and frequency, this inverter should be regulated. The synchronization is generally supplied using the voltage difference between these two, grid voltage, and the generator voltage. For the input of a boost converter, Fig. 3 provides a fixed DC voltage. To vary the Thevenin equivalent system resistance after rectification, the input current may be controlled, assuming a lossless converter. Although using multiple modules has an outcome on achieving enhanced overall waveforms, more conditioning is required for grid connectivity. There are numerous wave energy conversion structures with various amplitudes, frequencies, and phases of output voltages. If multiple devices are wired together, DC bus voltage differences may be reduced. For higher suppression of DC bus voltage variations, capacitor tanks should be placed after the rectification point. For the sustainability of the electricity supply to the grid, the capacitor bank serves as a short-term energy buffer if one of the systems fails to strike an incidence wave for the small period of time. Mostly, to test the neutral point and the output filter of the inverter, these capacitors are used. The output of the linear generator terminals is first transformed to DC voltage and then processed to regulate the generator's voltage and output power. A large capacitor is expected to obtain sufficient voltage control efficiency in terms of the critical oscillations in the output. If the output voltage of the rectifier is the input voltage, the converter can be improved. A DCDC boost converter running in the current control mode is used on a constant basis. The current mode of control makes it feasible to efficiently activate the linear generator.

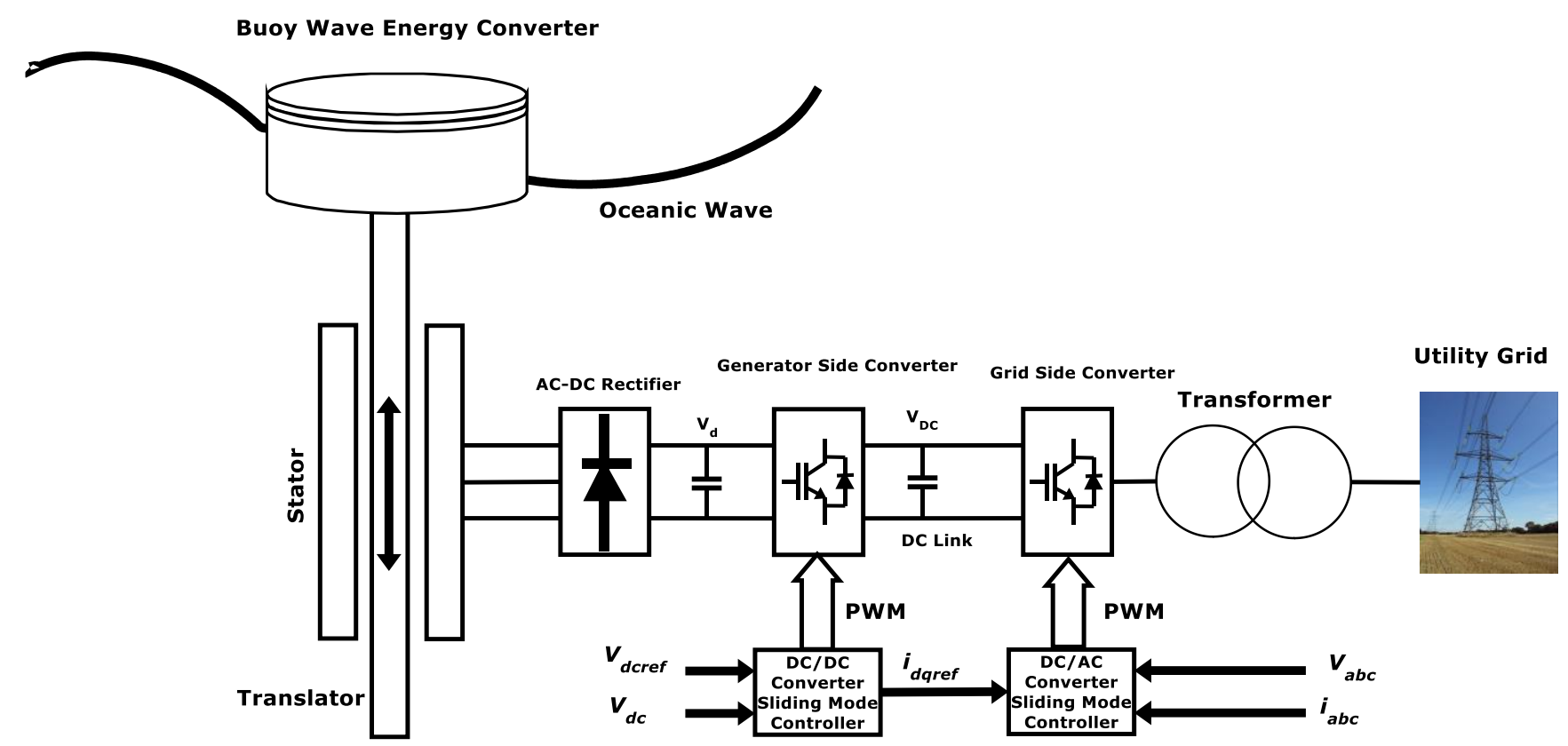

Fig. 1. Basic configuration of grid connected direct drive WEC based on a linear permanent magnet generator. 


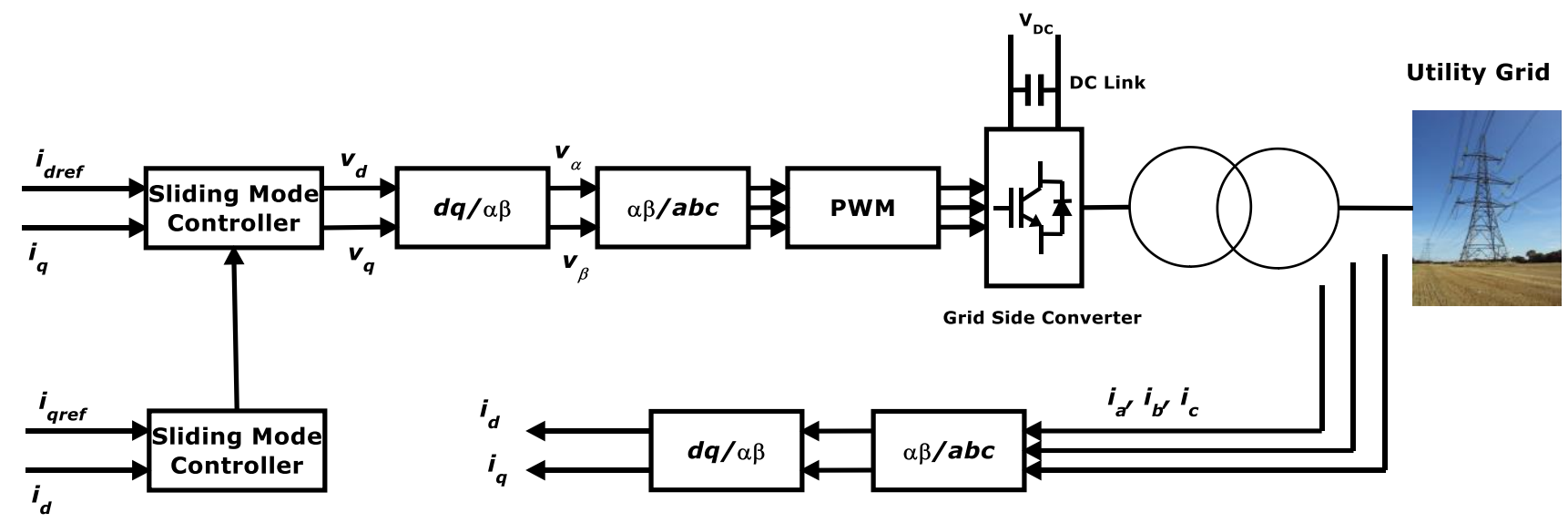

Fig. 2. Synchronous reference frame based Sliding Mode controller.

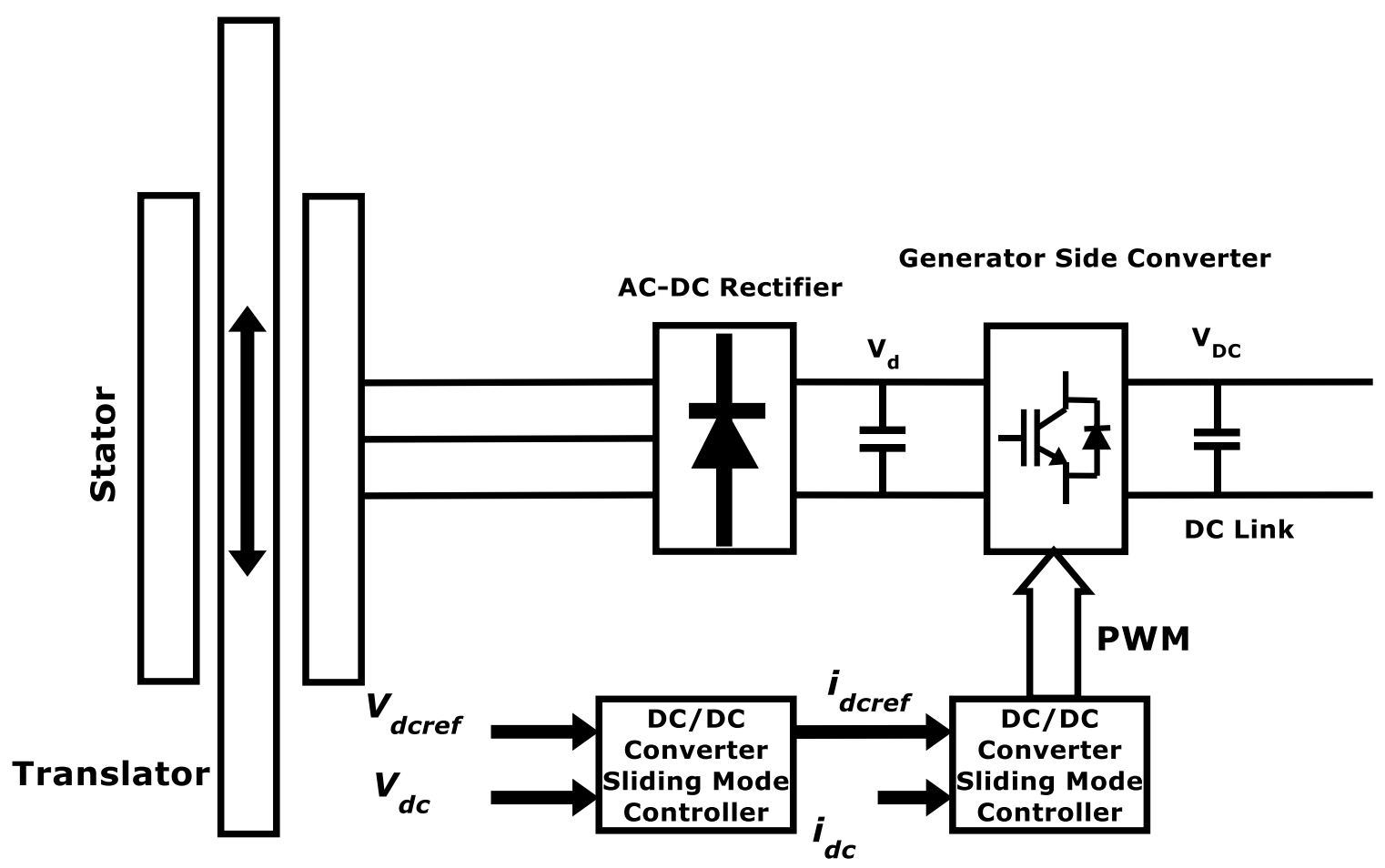

Fig. 3. The bidirectional dc/dc converter power block diagram.

\section{PROBLEM FORMULATION}

In certain studies, the mechanics of linear electric generators are expressed similarly to rotary electricity. They are represented in the reference frame of the rotor, often referred to as the dq frame. The key value of the dq models is that all sinusoidal variables function as direct-current quantities. Equations in the dq frame for the LPMG generator are given as follows:

$$
\begin{aligned}
& V_{s d}=R_{s} i_{s d}+L_{s} \frac{d}{d t} i_{s d}+\frac{\pi}{\tau} x L_{s} i_{s q} \\
& V_{s q}=R_{s} i_{s q}+L_{s} \frac{d}{d t} i_{s q}+\frac{\pi}{\tau} x\left(\lambda_{P M}-L_{s} i_{s d}\right)
\end{aligned}
$$

where $\mathrm{x}$ represents the translator's linear momentum, consistent with the heaving buoy's rotation, and $\tau$ is pole width of the pole.
There are two sections of the suggested full control block diagram. One is for the current direct current control of the direct current bus interface converter and the other is for the device's lateral power. For regulating the magnitude and speed of rotor flux, there are two grid side regulators. This then generates the current reference matrix of the stator. A current model estimator of rotor flux is used to measure the rotor flux vector. The direct current relation is always vulnerable in this system to the absence of a transition. The comparison direct current is given and sent to the directcurrent rail of the network converter. From the study of the stator current relation, the torque and the rotor flux strength are known. Functions for costing can also be stated as:

$$
\begin{aligned}
& J_{1}=\left|i_{d}^{r e f}-i_{d}(k+1)\right|^{2} \\
& J_{2}=\left|i_{q}^{\text {ref }}-i_{q}(k+1)\right|^{2}
\end{aligned}
$$

To improve operational efficiency, especially the dynamic response of the direct current bus interface converter, multiobjective particle swarm optimization is applied to this configuration. The direct current at the instant kth refers to 
the side voltages of the direct current. The measured side voltage of direct current and information of direct current data at each measurement interval is the proposed scheme. Using the future output direct current interface voltage converter, the direct current at $(\mathrm{k}+1)$ instant can be measured. An equation representing the weighted average of the NMSE variables between the goal values and the production plant determines the usefulness of the shift in the gains. In this way, the task of maximizing device output during transient fluctuations can be achieved by deciding optimum values for the controller's gains. The variations of NMSE among the target values and the variables of plant output are described as:

$$
\begin{aligned}
& J_{3}=N M S E_{V D C}=\frac{\sum\left(V_{D C}-V_{D C-r e f}\right)^{2}}{\sum\left(V_{D C-r e f}\right)^{2}} \\
& J_{4}=N M S E_{I D C}=\frac{\sum\left(I_{D C}-I_{D C-r e f}\right)^{2}}{\sum\left(I_{D C-r e f}\right)^{2}}
\end{aligned}
$$

\section{RESULT AND DISCUSSION}

The Sliding mode MOPSO based control system for the oceanic generation system with LPMSG has been developed and verified Sim Power System toolbox of Matlab/Simulink Software. To produce a direct power reference, the proposed MOPSO Sliding Mode strategy was tested for validity and adopted. Verify the efficiency of strong power tracking, while checking the feasibility of the MOPSO-based control technique suggested. These results are contrasted with those obtained using the PID controller and the sliding mode controller with constant gains in order to compare the increase obtained in the system dynamic output with use of sliding mode MOPSO procedure to design the controller gains. The MOPSO was used to attain the optimum gain for DC bus converter and service grid converter sliding mode controller for the same operating condition. The behaviour of the converter depends on the regulation mechanism. The performance of the converter during transient fluctuations can be increased if the controllers are well tuned. Tuning controllers, though, are repetitive and a range of optimum parameters is difficult to obtain manually. The MOPSO algorithm was introduced to find the optimum parameters of the sliding mode controller automatically in order to refine certain fitness tasks. The aim is to rise the total dynamic efficiency of LPMSG when, when measuring the optimum gains through the MOPSO procedures. The electrical network is vulnerable to severe electrical disturbances and faults. The following adjustments have been made to demonstrate the effectiveness of the proposed sliding mode MOPSO technique. It should be remembered that the expected velocity accurately tracks the actual one. It converges with it almost instantaneously. Fig. 4-6 show DC voltage (Vdc V) of the DC bus. The simulation results indicate that the oceanic generation system has a very stable DC voltage. Fig. 7-9 also display the DC bus current, which demonstrates that strong steady state and volatile outputs are provided by the proposed controller and exhibits excellent tracking capabilities. Fig. 10-21 show the ratio of isd, isq and calculated currents on the grid side and the electricity flowing through the power grid, respectively, active $(\mathrm{P})$ and reactive $(\mathrm{Q})$. They explain that both the reactive power Q and the current isq are regulated to zero, stressing that the power grid does not exchange reactive power. In contrast, as expected with each increase in sea speed, an increase in the current portion of the isd and the active power $\mathrm{P}$ occurs. At any speed of flow, the machine still produces full power. Thus, the system is still controlled by the proposed controller at the highest power point. These simulation results show that the hybrid generation system's integration and automatic power fluctuation are successful. The sliding mode controller based on MOPSO confirms that the input current and the established torque firmly follow the order current and the reference generator torque. It is recalled that reference torque direction of the generator always matches the turbine's maximum torque. Thus, using the control technique suggested by multi-objective particle swarm optimization, the maximum turbine torque can always be monitored at any flow rate without using any flow sensors.

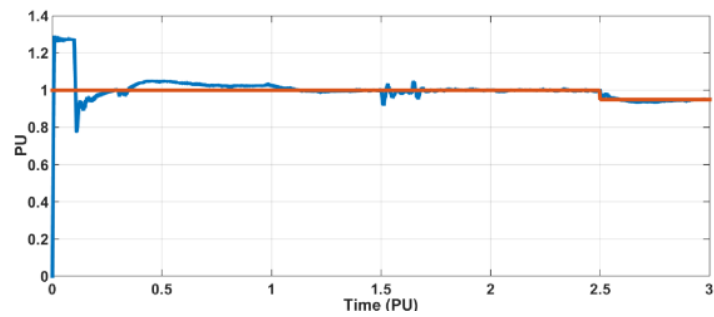

Fig.4. DC Bus Voltage Simulated Waveforms using PID Controller.

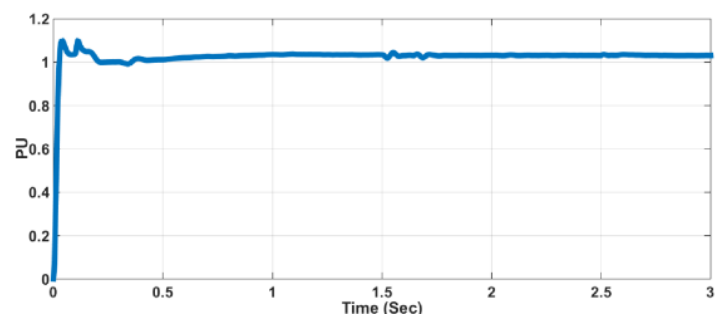

Fig. 5. Simulated DC Bus Voltage waveforms using Controller Sliding Mode.

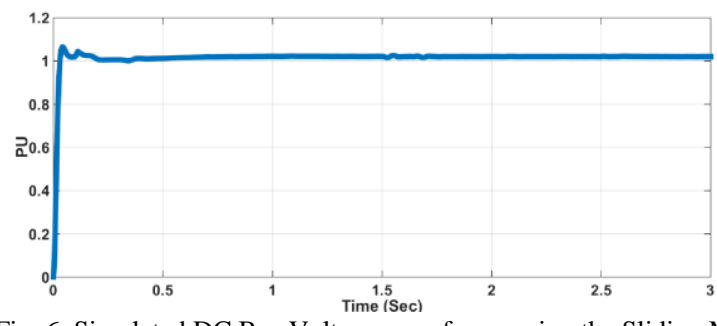

Fig. 6. Simulated DC Bus Voltage waveforms using the Sliding Mode MOPSO Controller.

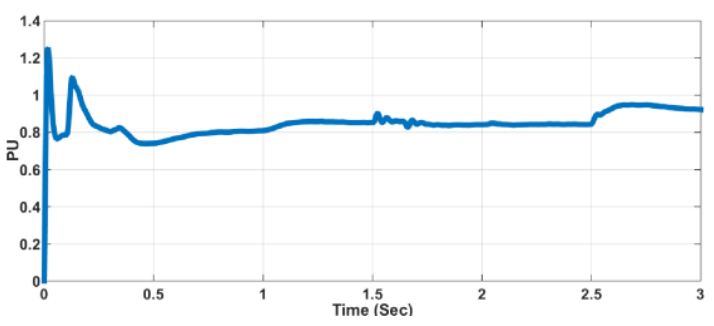

Fig. 7. Simulated DC Bus Current Waveforms using PID Controllers. 


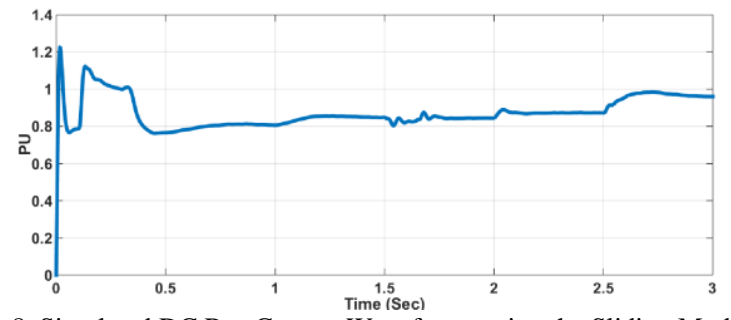

Fig. 8. Simulated DC Bus Current Waveforms using the Sliding Mode Controller.

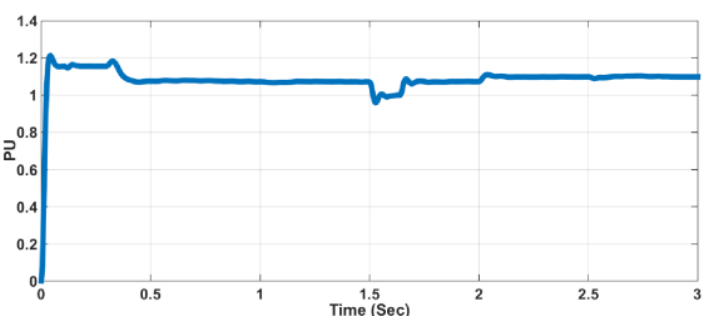

Fig. 9. Simulated DC Bus Current Waveforms using the MOPSO Controller Sliding Mode.

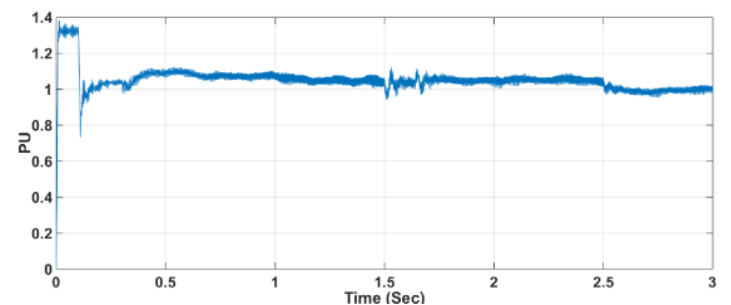

Fig. 10. Simulated waveforms of Direct Axes Current Id using PID Controller.

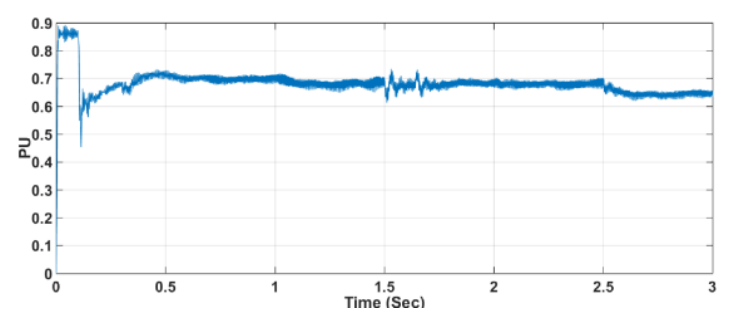

Fig. 11. Simulated waveforms of Direct Axes Current Id using Sliding Mode Controller.

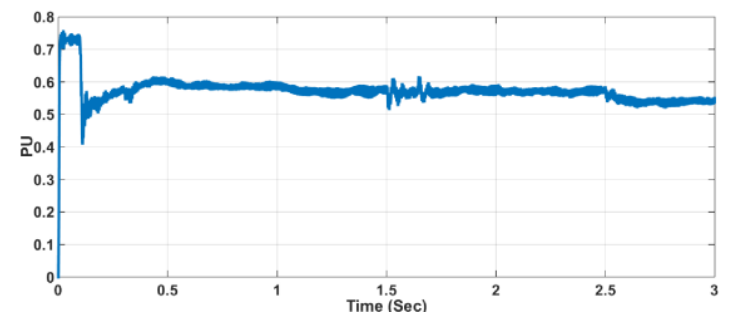

Fig. 12. Simulated waveforms of Direct Axes Current Id using Sliding Mode MOPSO Controller.

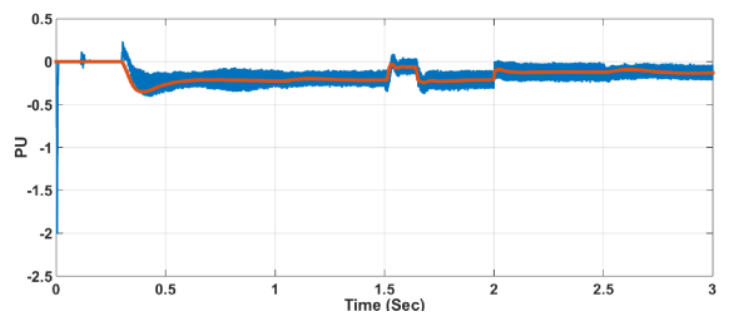

Fig. 13. Simulated waveforms of Quadrature Axes Current Iq using PID Controller.

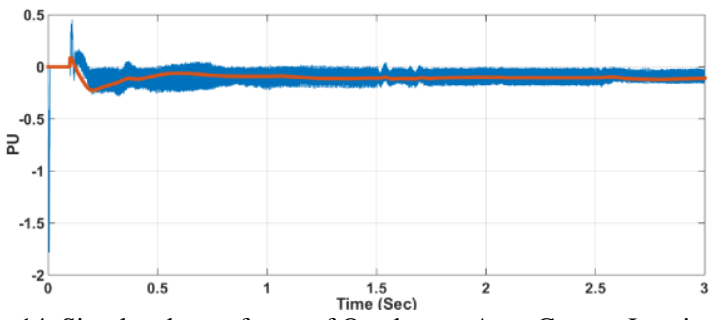

Fig. 14. Simulated waveforms of Quadrature Axes Current Iq using Sliding Mode Controller.

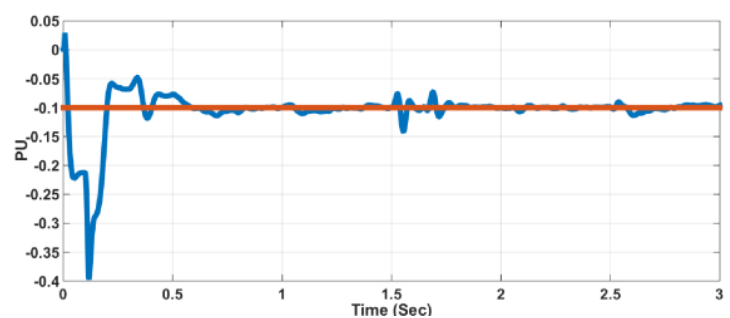

Fig. 15. Simulated waveforms of Quadrature Axes Current Iq using Sliding Mode MOPSO Controller.

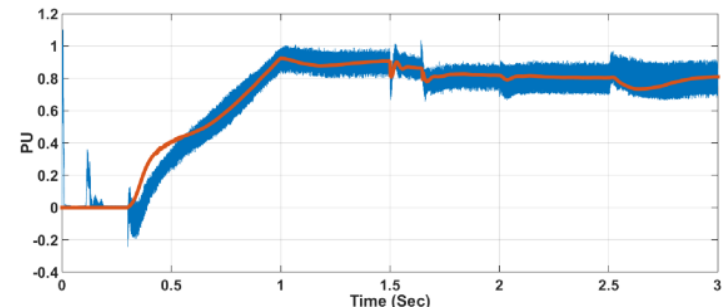

Fig. 16. Simulated DC Bus Power waveforms using the PID Controller.

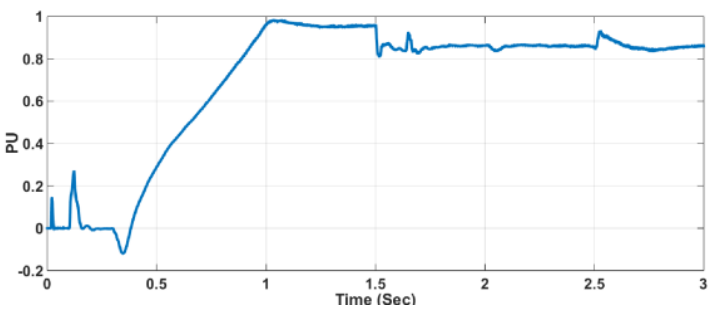

Fig. 17. Simulated DC Bus Power waveforms using Sliding Mode Controllers.

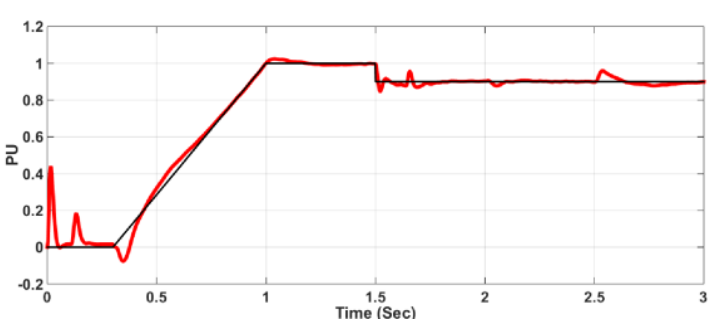

Fig. 18. Simulated DC Bus Power waveforms using the MOPSO Controller Sliding Mode.

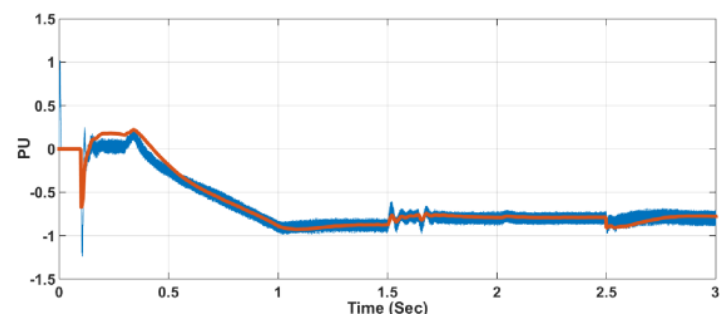

Fig. 19. Simulated waveform of the Reactive Power Q using PID Controller. 


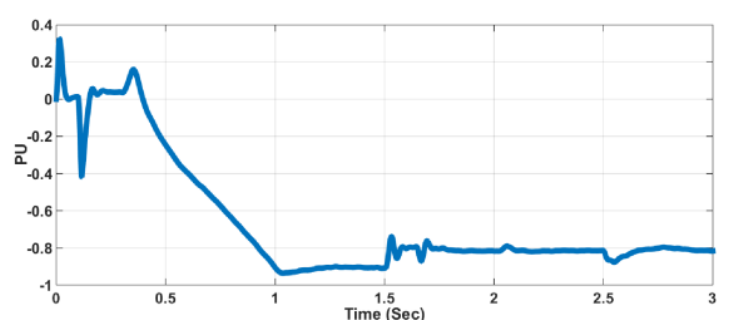

Fig. 20. Simulated waveforms of the Reactive Power Q using Sliding Mode Controller.

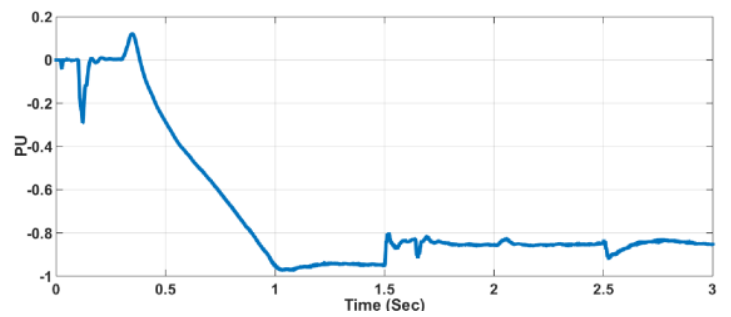

Fig. 21. Simulated waveforms of the Reactive Power Q using Sliding Mode MOPSO Controller.

\section{CONCLUSION}

An optimal MOPSO sliding mode control scheme has been proposed in this article to increase the economic viability of the Grid-Connected direct drive ocean wave energy extraction method. The proposed optimal control strategy aims to minimize power volatility from feeding to the distribution power grid and to preserve the studied system's steady operation while achieving optimal power extractions from the wave power generation system. Both modal analysis and time-domain simulations of the permanent magnet linear generator were carried out in real time in order to analyze dynamic efficiency of studied method under different operating conditions. The technique governs the operating time of a single-switch three-phase boost rectifier attached to the output terminals of PMLG. After implementing the proposed strategy under different operating conditions, simulations were performed to test the wave energy converter's output. From simulation outcomes, it can be inferred that this proposed control system is capable of efficiently smoothing out fluctuations in power. And, though harvesting the full power from the wave power generation system, it preserves the reliable function of the studied system under varying operating conditions. The results have shown satisfactory efficiency for various sea-state and electricalloading conditions.

\section{REFERENCES}

[1] Sung-Won Seo, Kyung-Hun Shin, Min-Mo Koo, Keyyong Hong, IckJae Yoon, Jang-Young Choi, "Experimentally Verifying the Generation Characteristics of a Double-Sided Linear Permanent Magnet Synchronous Generator for Ocean Wave Energy Conversion' IEEE Transactions on Applied Superconductivity, 2020, Volume: 30, Issue: 4.

[2] Tao Xia, Haitao Yu, Rong Guo, Xiaomei Liu, "Research on the FieldModulated Tubular Linear Generator with Quasi-Halbach Magnetization for Ocean Wave Energy Conversion" IEEE Transactions on Applied Superconductivity, 2018, Volume: 28, Issue: 3.

[3] Yunfei Li, Qiyu Guo, Manjuan Huang, Xin Ma, Zhaohui Chen, Huicong Liu, Lining Sun, "Study of an Electromagnetic Ocean Wave Energy Harvester Driven by an Efficient Swing Body Toward the SelfPowered Ocean Buoy Application” IEEE Access, 2019, Volume: 7.
[4] Basel Alnajjab, Rick S. Blum, "Estimating Waveforms of Ocean Waves to Enhance the Efficiency of Ocean Energy Conversion" IEEE Transactions on Sustainable Energy, 2017, Volume: 8, Issue: 1

[5] Dionisio Ramirez; Juan Pablo Bartolome; Sergio Martinez; Luis Carlos Herrero; Marcos Blanco "Emulation of an OWC Ocean Energy Plant with PMSG and Irregular Wave Model" IEEE Transactions on Sustainable Energy, 2015, Volume: 6, Issue: 4.

[6] Nathan Tom, Ronald W. Yeung, "Experimental Confirmation of Nonlinear-Model- Predictive Control Applied Offline to a Permanent Magnet Linear Generator for Ocean-Wave Energy Conversion” IEEE Journal of Oceanic Engineering, 2016, Volume: 41, Issue: 2.

[7] Sunil Kumar Mishra, Shubhi Purwar, Nand Kishor, "Event-Triggered Nonlinear Control of OWC Ocean Wave Energy Plant" IEEE Transactions on Sustainable Energy, 2018, Volume: 9, Issue: 4

[8] M. Takao and T. Setoguchi, "Air turbines for wave energy conversion," International Journal of Rotating Machinery, vol. 2012, Article ID 717398, 10 pages, 2012.

[9] A. Thakker, J. Jarvis, and A. Sahed, "Quasi-steady analytical model benchmark of an impulse turbine for wave energy extraction,' International Journal of Rotating Machinery, vol. 2008, Article ID536079, 12 pages, 2008.

[10] B. Drew, A. R. Plummer, and M.N. Sahinkaya, "A review of wave energy converter technology," Proceedings of the Institution of Mechanical Engineers, Part A: Journal of Power and Energy, vol. 223, no. 8, pp. 887-902, 2009.

[11] L. Huang, J. Liu, H. Yu, R. Qu, H. Chen, and H. Fang, "Winding configuration and performance investigations of a tubular superconducting flux-switching linear generator," IEEE Transactions on Applied Superconductivity, vol. 25, no. 3, 2015.

[12] M.-J. Jin, C.-F. Wang, J.-X. Shen, and B. Xia, "A modular permanentmagnet flux-switching linear machine with fault tolerant capability," IEEE Transactions on Magnetics, vol. 45, no. 8, pp. 3179-3186, 2009

[13] L. Huang, H. Yu, M. Hu, J. Zhao, and Z. Cheng, "A novel flux switching permanent-magnet linear generator for wave energy extraction application," IEEE Transactions on Magnetics, vol. 47, no. 5, pp. 1034-1037, 2011

[14] L. Huang, H. Yu, M. Hu, C. Liu, and B. Yuan, "Research on a tubular primary permanent-magnet linear generator for wave energy conversions," IEEE Transactions on Magnetics, vol. 49, no. 5, pp. 1917-1920, 2013.

[15] V. D. Colli, P. Cancelliere, F. Marignetti, R. Di Stefano, and M. Scarano, "A tubular-generator drive for wave energy conversion," IEEE Transactions on Industrial Electronics, vol. 53, no. 4, pp. $1152-$ 1159, 2006.

[16] J. F. Pan, Y. Zou, N. Cheung, and G.-Z. Cao, "On the voltage ripple reduction control of the linear switched reluctance generator for wave energy utilization," IEEE Transactions on Power Electronics, vol. 29, no. 10 , pp. 5298-5307, 2014.

[17] Ilyas, A.; Kashif, S.A.R.; Saqib, M.A.; Asad, M.M. Wave electrical energy systems: Implementation, challenges and environmental issues Renew. Sustain. Energy Rev. 2014, 40, 260-268.

[18] Truong, D.Q., Ahn, K.K., Development of a novel point absorber in heave for wave energy conversion. Renew. Energy 2014, 65, 183-191.

[19] Ozkop, E., Altas, I.H., Control, power and electrical components in wave energy conversion systems: A review of the technologies. Renew. Sustain. Energy Rev. 2017, 67, 106-115.

[20] Yavuz, H., Stallard, T.J., McCabe, A.P., Aggidis, G.A., Time series analysis-based adaptive tuning techniques for a heaving wave energy converter in irregular seas. J. Power Energy 2007, 221, 77-90.

[21] Hals, J., Falnes, J., Moan, T. A, Comparison of selected strategies for adaptive control of wave energy converters. J. O shore Mech. Arct. Eng. 2011, 133, 031101.

[22] Tom, N., Yeung, R.W., Experimental Confirmation of NonlinearModel-Predictive Control Applied Online to a Permanent Magnet Linear Generator for Ocean-Wave Energy Conversion. IEEE J. Ocean. Eng. 2016, 41, 281-295.

[23] Wu, F., Zhang, X.P., Ju, P., Sterling, M.J.H., Optimal control for AWSbased wave energy conversion system. IEEE Trans. Power Syst. 2009, 24, 1747-1755.

[24] Vermaak, R., Kamper, M.J., Experimental evaluation and predictive control of an air-cored linear generator for direct-drive wave-energy converters. IEEE Trans. Ind. Appl. 2012, 48, 1817-1826.

[25] Shek, J.K.H.; Macpherson, D.E., Mueller, M.A., Xiang, J., Reaction force control of a linear electrical generator for direct drive wave energy conversion. IET Renew. Power Gener. 2007, 1, 17-24.

[26] Vermaak, R., Kamper, M.J., Construction and control of an air-cored permanent magnet linear generator for direct drive wave energy converters. In Proceedings of the IEMDC, Niagara Falls, ON, Canada, 15-18 May 2011; pp. 1076-1081. 
[27] Ekström, R., Ekergård, B., Leijon, M., Electrical damping of linear generators for wave energy converters-A review. Renew. Sustain. Energy Rev. 2015, 42, 116-128.

[28] Li, B., Macpherson, D.E., Shek, J.K.H., Direct drive wave energy converter control in irregular waves. In Proceedings of the IET Conference Renewable Power Generation, Edinburgh, UK, 6-8 September 2011; pp. 1-6.

[29] Falnes, J., Ocean Waves and Oscillating Systems. Linear Interactions including Wave-Energy Extraction; Cambridge University Press: Cambridge, UK, 2004.

[30] Yang, J., Huang, L., Hu, M., Jiu, C., Zhao, D. Research on a control strategy of the flux switching permanent magnet linear generator for wave energy extraction. In Proceedings of the 18th International Conference on Electrical Machines and Systems, Pattaya, Thailand, 25-28 October 2015; pp. 1666-1670.

[31] Oetinger, D.; Magaña, M.E.; Sawodny, O. Centralised model predictive controller design for wave energy converter arrays. IET Renew. Power Gener. 2015, 9, 142-153.

[32] Richter, M.; Magaña, M.E.; Sawodny, O.; Brekken, T.K.A. Power optimization of a point absorber wave energy converter by means of linear model predictive control. IET Renew. Power Gener. 2014, 8 , 203-215.

[33] Yavuz, H.; Stallard, T.J.; McCabe, A.P.; Aggidis, G.A. Time series analysis-based adaptive tuning techniques for a heaving wave energy converter in irregular seas. J. Power Energy 2007, 221, 77-90.

[34] Bode, G.H.; Loh, P.C.; Newman, M.J.; Holmes, D.G. An improved robust predictive current regulation algorithm. IEEE Trans. Ind. Appl. 2005, 41, 1720-1733.

[35] Summers, T.; Betz, R.E. Dead-time issues in predictive current control. IEEE Trans. Ind. Appl. 2004, 40, 835-844.

[36] Murai, Y.; Riyanto, A.; Nakamura, H.; Matsui, K. PWM strategy for high frequency carrier inverters eliminating current clamps during switching deadtime. In Proceedings of the IEEE Industry Applications Society (IAS) Annual Meeting, Houston, TX, USA, 4-9 October 1992; pp. 317-322.

[37] Hong, Y.;Waters, R.; Boström, C.; Eriksson, M.; Engström, J.; Leijon, M. Review on electrical control strategies for wave energy converting systems. Renew. Sustain. Energy Rev. 2014, 31, 329-342.

[38] de la Villa-Ja'en, A.; Garc'1a Santana, A.; Montoya, D. Maximizing output power of linear generator for wave energy conversion. Int Trans. Electr. Energy Syst. 2014, 24, 875-890.

[39] Montoya, A.D.E.; de la Villa-Ja'en, A.; Garc'ia Santana, A. Considering linear generator copper losses on model predictive control for a point absorber wave energy converter. Energy Convers. Manag. $2014,78,173-183$ 